\title{
Grain Quality Research of Rice for Ensuring Nutritional Food Security
}

\author{
H B Shozib1 ${ }^{*}$, M A Siddiquee ${ }^{1}$, N M F Rahman², M A A Mamun², M A R Sarkar ${ }^{3}$,S M H A Rabbi ${ }^{4}$, \\ M U Salam ${ }^{5}$ and MS Kabir 6
}

\begin{abstract}
Per capita rice consumption in Bangladesh is in a decreasing trend. Considering the constant loss of per capita daily dietary energy @ $0.028 \%$ year ${ }^{-1}$, nutrition-based prediction of daily dietary energy intake (kcal) may be reduced to 2201 and $2188 \mathrm{kcal}$ for our population by 2030 and 2050, respectively. We are optimistic that consuming per capita rice consumption of $365 \mathrm{~g}$ and $363 \mathrm{~g}$ (dry wt. basis) in 2030 and 2050, respectively will help to attain the current trends of $59.0 \%$ of Calorie intake from rice only. Appropriate amount of rice intake including incorporating rice-based products in our daily diet, we will able to attain daily required dietary allowance and combination of both may ensure nutritional security along with food security in Bangladesh in a way to effective utilization of the rice grain. Rice is nutraceutically enriched because of the presence of phenolic compounds, flavonoids and antioxidants. Research thrust of BRRI is to focus on releasing nutraceutically enriched HYVs such as high zinc, high iron, beta carotene (A Vit A precursor) enriched antioxidant rice etc. Gluten free rice-based bakery products have potential to get popularize in Bangladeshi population with ensuring high nutritional value and effective management of controlling non-communicable diseases since lesser amount of rice carbohydrates are being utilized in formulating products such as rice biscuit, rice cake etc. BRRI has formulated gluten free rice-based energy dense product specially rice biscuit (ED 5.15) could be extended as a potential nutritionally balanced dry food application in malnutrition mitigation programme, school feeding nutritional programme and humanitarian relief operation replacing current wheat-based products.
\end{abstract}

Key words: Nutraceutical, malnutrition mitigation, gluten free rice-based bakery products. energy dense rice biscuit.

\section{INTRODUCTION}

The nutrient content of rice varies depending on rice soil, and the conditions they grow. A better understanding of the intrinsic factors that contribute to the overall rice grain quality will set the foundation for developing new breeding and selection strategies for combining high grain quality, with higher yield and nutritional value. Rice producing countries have the potential to generate higher export revenues by meeting the ever-increasing global demand for high-quality rice specially nutraceutical enriched premium quality rice. Bangladesh can not be an exception in this regard.

\section{The malnutrition scenario of the Bangladeshi population}

Humans need at least 49 different types of nutrients for their regular development and the majority of the required nutrients are supplied by cereals, particularly rice due to its staple role (Welch, 2004). Minerals play numerous beneficial roles due to the effect on both plant and human metabolism. The deficiencies or an insufficient intake of nutrients lead to several dysfunctions and diseases in humans, such as anemia for iron, stunting for zinc, and osteoporosis for calcium which are most prevalent in developing countries (Welch et al., 1999). Malnutrition in Bangladesh is alarmingly high since approximately $36.2 \%$ children of under five years of age are stunted, $15 \%$ are wasted and 33\% are underweight (Sunanda and Jahida, 2017). Both malnutrition and poverty hamper access to education especially the ability to learn. One in every five preschool or schoolaged children suffers from vitamin A deficiency in Bangladesh. Also, 33\% of preschool children

\footnotetext{
${ }^{1}$ Grain Quality and Nutrition Division, Bangladesh Rice Research Institute (BRRI), Gazipur-1701, Bangladesh; ${ }^{2}$ Agricultural Statistics Division, BRRI, Gazipur-1701, Bangladesh; ${ }^{3}$ Agricultural Economics Division, BRRI, Gazipur-1701, Bangladesh; ${ }^{4}$ Biotechnology Division, BRRI, Gazipur-1701, Bangladesh; ${ }^{5}$ Freelance Consultant (Agricultural Systems), BRRI, Gazipur-1701, Bangladesh; ${ }^{6}$ Director General, BRRI, Gazipur-1701, Bangladesh.
}

*Corresponding author's E-mail: shozib11@gmail.com (H B Shozib) 
are anemic, $9 \%$ of women have folate deficiency and $22 \%$ of women are suffering from Vit- $\mathrm{B}_{12}$ deficiency in our population. According to the National Micronutrients Survey 2011-2012, Bangladesh has a frequency of zinc deficiency is about $44.6 \%$ amongst preschool-age children and $57.3 \%$ amongst non-pregnant non-lactating women.

\section{Nutrient loss negatively correlates with the degree of milling}

The principle of rice milling is the removal of the husk (husking) followed by the rice bran (polishing), which gives us the edible portion (endosperm) of rice grain. Certain nutrients like fats, vitamins, proteins, and minerals are found in good concentration in germ and outer layers of endosperm i.e. bran portion of kernels. In 2007, Lamberts et al., showed that about $84.2 \%$ of kernel proteins are concentrated in outer endosperm, and upon milling further the concentration of proteins decreases. They found that $61 \%$ of most of the minerals are present in the bran fraction of the kernels whereas the core of the endosperm fraction mainly consists of starch $(84.6 \%)$ in the kernels. Milling is a phenomenon of wear that involves removing material from a solid surface either by mechanical action or by combinations of various actions such as rolling, impacting, or sliding. Commercial milling is a process consisting of various stages where firstly paddy or rough rice goes through the dehusking process and then the outer brown bran layer is removed during the whitening process. In the final step, the adhering bran is completely removed from the grain surface and is known as polishing. The quality of milled rice is depicted by two important parameters i.e., the whiteness of the kernel and yield of head rice (HRY). Rice can be milled by two methods i.e., abrasion milling and friction milling. When the rice grain is made to revolve inside a milling chamber, then the grain which gets in touch with the emery surface experiences abrasion type of milling while grain which rubs against each other experiences adhesive type of wear. In rice polishing, generally, a combination of both types of wear is used, as, no pure form of milling has yet been discovered. Rubber rolls were determined to be most suitable for laboratory scale milling operations as these increased the dehusking percentage but decreased the breakage of rice kernels. During milling operations, these nutrients are removed thus reducing the nutritive value of starch. The degree of milling (DOM) affects the concentration of nutrients. The proximate composition depends upon the degree to which the bran has been removed from the kernel surface. The rice subjected to lower DOM could lead to more nutrition which can assure better health of the consumers (Puri, 2014). The speed of the impeller cannot be taken as a sole criterion for optimization of impeller husker performance, as it depends on the size and shape of rice kernels also (Puri, 2014). This could be judged by a low husked ratio even if the impeller speed was at its optimum. The quality of rice milling is affected by the moisture content of paddy as well as the rotor speed of the whitener. Various experiments were performed using different cultivars and different types of milling material such as plywood, iron sheet, rubber, glass, and fiberglass. Milling in rubber roll huller was found to be the most effective for paddy but least for milled rice. In 2010, Firouzi et al., evaluated the performance of perforated screen size and blade rotor clearance for whitening of rice grain. During the milling process, the losses of minerals reached up to $84.7 \%$. Fukai and Godwin,(2007) milled brown rice cultivars and measured loss in iron content. The iron content of $25-84 \%$ was lost during the milling process.

\section{Functional properties of rice}

Rice is an important source of energy, hypoallergenic, easily digested, providing protein with higher nutritional quality, and 
has versatile functional nutraceutical properties. Rice has an important role in the relation between diet and health. several compounds with antioxidant activity have been identified in rice, including phenolic compounds, tocopherols, tocotrienols, and $\mathrm{Y}^{-}$ oryzanol (Iqbal et al., 2005). The phenolic compounds are mainly associated with the pericarp in rice; hence, the milling process reduces the concentration of these compounds in the grain. Besides, grains with darker pericarp colour, such as red and black rice, contain higher amounts of polyphenols (Tian et al., 2004; Zhou et al., 2004). The concentration of total phenolics in the grain has been positively associated with the antioxidant activity (Itani et al., 2002; Zhang et al., 2006). Therefore, it reduces oxidative stress (Ling et al., 2001), cancer (Hudson et al., 2000; Hu et al., 2003), blood lipids and related diseases, and hence prevents cardiovascular problems (Ling et al., 2001), and diabetes complications (Morimitsu et al., 2002; Yawadio et al., 2007).

\section{Water soluble vitamins in rice}

People intake thiamin Vit- $B_{1}$ for conditions related to low levels of thiamin (thiamin deficiency syndromes), including beriberi, inflammation of the nerves (neuritis) associated with pellagra, or pregnancy. Thiamin is also used for digestive problems including poor appetite, ulcerative colitis, diabetic pain, heart disease, alcoholism, aging, vision problems such as cataracts, glaucoma, motion sickness, improving athletic performance, preventing cervical cancer and progression of kidney disease in patients with type-2 diabetes, AIDS and boosting the immune system. Thiamin functions as a coenzyme in the metabolism of carbohydrates and branched-chain amino acids. Recommended Dietary Allowance (RDA) for adults is 1.2 and $1.1 \mathrm{mg}$ day $^{-1}$ for men and women, respectively. Riboflavin functions as a co-enzyme in numerous redox reactions. The RDA for riboflavin for adults is 1.3 and $1.1 \mathrm{mg}$ day $^{-1}$ for men and women (Institute of Medicine, 1998), respectively.

\section{Gluten-free rice-based bakery food products}

Food intolerance became an important public health concern, and the identification of effective strategies for prevention is obligatory. There is an increasing incidence of coeliac disease or other allergic reactions/intolerances to gluten. This intolerance can be at any age, from early childhood to the elderly. Since rice does not have gluten protein naturally, it has advantages to prepare rice-based bakery products over wheat-based products. Bangladesh Rice Research Institute (BRRI) has formulated several gluten-free rice-based products such as rice biscuit, cake, bread and bun, and gluten-free rice-based processed food items have the potential scope in Bangladesh specially for malnutrition mitigation approach, school feeding nutrition programme, disaster management programme, etc. In this regard, BRRI has formulated energy-dense nutraceutically enriched rice-based bakery food formulation especially biscuits having energy density ranges from ED 5.0-5.5 per 100 $\mathrm{g}$ serving. Rice-based balanced and nutritious food intake might reduce rice consumption from the current rate of $367 \mathrm{~g}_{\text {capita }}{ }^{-1}$ day $^{-1}$ to $363 \mathrm{~g}$ capita $^{-1}$ day $^{-1}$ or lesser for the Bangladeshi population. Since floating urban street children are classified as the most vulnerable group in Bangladeshi population so, nutraceutically enriched rice-based bakery food products might play a role in shifting malnutrition status in this regard. In addition, in quest to attain the required daily dietary allowance on scale of average of $2000 \mathrm{kcal}$, rice-based energy-dense food might assist as a supplementary diet and it will be helpful to attain the SDG goal for hunger-free and sustain food security in Bangladesh in a way to properly and effectively utilizing the rice grain. Kabir et al., (2020) has also emphasized the established value of production for ensuring the rice productivity double. 
In Bangladesh, rice is synonymous to food and has been the customary source of carbohydrates and proteins since the ancient days. BRRI has developed $106 \mathrm{HYVs}$ including both inbred and hybrid. At present, total clean rice production is about $34.9 \mathrm{MT}$ which fulfills the domestic requirement to feed more than 168 million populations. So, it is high time to focus our grain quality and nutrition research towards grain nutraceutical properties especially mineral profiling, phytate estimation, antioxidant profiling, volatile compounds including aroma quantization, low glycemic content, water, fatsoluble vitamin profiling, etc. to reveal its ability to combat with non-communicable diseases (NCD) especially cancer, cardiovascular disease, diabetes, and obesity.

With the above background, this article undertook three specific objectives in relation to rice grain quality in Bangladesh: (i) presentation of dietary energy changing status, (ii) highlighting the scenarios of nutraceutical rice research activities at BRRI, and (iii) developing and mapping the action plan for three decades on improving nutraceutically enriched rice grain quality.

\section{METHODOLOGY}

A total of 72 high yielding varieties (HYV) including 68 inbred and four hybrid rice were surveyed for Glycemic Index (GI) screening in vivo experiment (Shozib et al., 2017a) rat model and GI value was measured by AUC (Area under the curve) method (Haffner, 1986; slightly modified by both Psyrogiannis, 2003 and Keh, 2004). Sixty-eight BRRI HYVs were analyzed for mineral profiling of $\mathrm{Zn}, \mathrm{Fe}, \mathrm{Ca}$, and $\mathrm{P}$ elements by standard AOAC methods (AOAC, 1995) for AAS (Atomic absorption spectrophotometer), and 35 BRRI developed HYVs were analyzed for water-soluble vitamins such as thiamine and riboflavin (Shozib et al.,2017b; Shozib et al.,2018a) by HPLC methods mentioned in ASEAN Manual of Food Analysis (Prapasri et al., 2011).
Physicochemical parameters were measured following IRRI evaluation standard SES (IRRI, 2013). Antioxidant properties such as Total Phenolic Content (TPC, mg GAE g ${ }^{-1}$ dry weight), Total antioxidant activity (TAC, AAE $\mathrm{g}^{-1}$ dry weight Assay, Ferric ion reducing antioxidant power assay (FRAP, AAE g- ${ }^{-1}$ dry weight ) and DPPH radical scavenging activity of rice were measured by Singleton et al., (1999), phospho-molybdenum assay by Prieto (1999) and Oyaizu (1986) by 1, 1-dipheyl-2picryl-hydrazyl (DPPH) using the method described by Oktay et al.,(2003) respectively. The water-soluble vitamins are extracted from the rice powder by acid hydrolysis followed by enzymatic hydrolysis. Thiamin and riboflavin in rice were measured by HPLC method (ASEAN Manual of Food Analysis).

In the baseline survey (Saima et al.,2020) on dietary intake of street children our target population was both boys and girls of 4-12 years old street children. We have interviewed 384 street children from above mentioned 20 hot spots in the capital city of Dhaka. Using Cochran Equation, we found the sample size 384 .

$$
\text { Sample size }=\frac{Z^{2} P(1-P)}{E^{2}}
$$

The value of $\mathrm{Z}$ is found in statistical tables which contains the area under the normal curve. $Z=1.96$ for $95 \%$ level of confidence. $P$ is the estimated proportion of an attribute that is present in the population.

$E^{2}$ is the desired level of precision.

$$
\begin{aligned}
\text { Sample size }=\frac{Z^{2} P(1-P)}{E^{2}}=\frac{1.96^{2} \times 0.5 \times(1-0.5)}{0.05^{2}} \\
=384.16 \approx 384
\end{aligned}
$$

Rice-based bakery products were formulated according to the general guideline of Biscuit and cake of BSTI, Bangladesh. Gluten-free energy-dense rice biscuit (EDRB) and energydense rice cake (EDRC) were also formulated.

Per capita rice consumption (kcal) projection was made using continuous exponential 
growth model $y=a(1+r)^{x}$. Here $y=$ per capita rice consumption in kcal, $\mathrm{r}=$ growth rate, $\mathrm{a}=$ initial value and $x=$ time interval. Per capita rice consumption data of BBS-HIES 2016 was selected for the initial value. Observed kcal data of BBS were used as 2244, 2240, 2238, 2318, and 2210 for 1995, 2000, 2005, 2010, and 2016 respectively to calculate the growth rate. We have predicted the daily dietary energy intake projection for 2050 considering all the food components contribution into account.

\section{RESULTS AND DISCUSSION}

\section{Daily dietary energy intake projection}

Since rice is the major dietary energy source among the cereal crops for our population, so rice should be nutraceutically enriched in terms of antioxidants, minerals, having low glycemic and higher protein, etc. In order to attain SDG goals on safe and nutritional food, newly released HYVs will have to be aligned with special nutraceutical properties such as antioxidants enriched and high content of minerals especially zinc (>27.50 ppm), iron (>10.00 ppm), and vitamin A (>8.64 ppm) etc. Reviewing the per capita per day Calorie (kcal) data from the year 1995 to 2016, we observed that these years had declining trends of $0.028 \%$ year $^{-1}$. Considering the constant loss of per capita daily dietary energy @ 0.028\% year-1, nutrition-based prediction of daily dietary energy intake (kcal) might be reduced to 2201 and $2188 \mathrm{kcal}$ for our population by 2030 and 2050, respectively (Table 1 and Fig. 1). We are hopeful that consuming per capita rice consumption of $365 \mathrm{~g}$ and $363 \mathrm{~g}$ (dry wt. basis) in 2030 and 2050, respectively will help to attain the current trends of $59.0 \%$ of Calorie (kcal) intake from rice only.

Energy plays a vital role in our daily activities. Fruits and vegetables are treated as an energy booster and provide a diversified, flavoured, colourful, tasty, low caloric, and protective, micronutrient rich diet. A healthy diet contains fruits, vegetables, legumes (e.g. lentils, beans), nuts, and whole grains (WHO, 2020). The total per capita food intake (g) of the Bangladeshi population decreased from 2010 to 2016 by $2.5 \%$. Per capita rice and wheat (g) intakes decreased by $11.77 \%$ and $62.32 \%$ from 2010 to 2016 but simultaneously per capita pulses, vegetables, fish, meat, and egg intake (g) increased by $9.09,0.73,26.65,29.99$, and $87.31 \%$, respectively for the same period of time (HIES, 2016). The overall calorie intake per capita per day has decreased to $2210 \mathrm{kcal}$ in 2016 from $2308 \mathrm{kcal}$ in 2010 (a decrease of $4.23 \%$ ). This is may be due to a substantial decrease in rice consumption in 2016 compared to 2010 (HIES, 2016).

Table 1. Prediction of per capita rice consumption in Bangladesh.

\begin{tabular}{llccccc}
\hline Year & Source & $\begin{array}{c}\text { Energy intake }(\mathrm{kcal} \\
\left.\text { person }^{-1} \text { day }^{-1}\right)\end{array}$ & $\begin{array}{c}\text { Rice intake }(\mathrm{g} \\
\left.\text { person }^{-1} \text { day }^{-1}\right)\end{array}$ & $\begin{array}{c}\text { Energy from } \\
\text { rice }(\mathrm{kcal})\end{array}$ & $\begin{array}{c}\text { Calorie } \\
(\%)\end{array}$ & $\begin{array}{c}\text { Rice intake }(\mathrm{kg} \\
\left.\text { person }^{-1} \text { year }^{-1}\right)\end{array}$ \\
\hline 2016 & HIES, BBS & 2210 & 367 & 1307 & 59 & 134 \\
2020 & Projected $^{*}$ & 2207 & 366 & 1302 & 59 & 134 \\
2025 & Projected $^{*}$ & 2204 & 365 & 1300 & 59 & 133 \\
2030 & Projected $^{*}$ & 2201 & 365 & 1299 & 59 & 133 \\
2035 & Projected $^{*}$ & 2198 & 364 & 1297 & 59 & 133 \\
2040 & Projected $^{*}$ & 2195 & 364 & 1295 & 59 & 133 \\
2045 & Projected $^{*}$ & 2192 & 363 & 1293 & 59 & 133 \\
2050 & Projected $^{*}$ & 2188 & 363 & 1291 & 59 & 132 \\
\hline
\end{tabular}

*Projection was made by considering the constant loss of per capita daily dietary energy @ 0.028\% year-1 using a continuous exponential growth model and $100 \mathrm{~g}$ serving of raw rice generates approximately $356 \mathrm{kcal}$ of energy. HIES and BBS denotes Household Income and Expenditure Survey and Bangladesh Bureau of Statistics. 


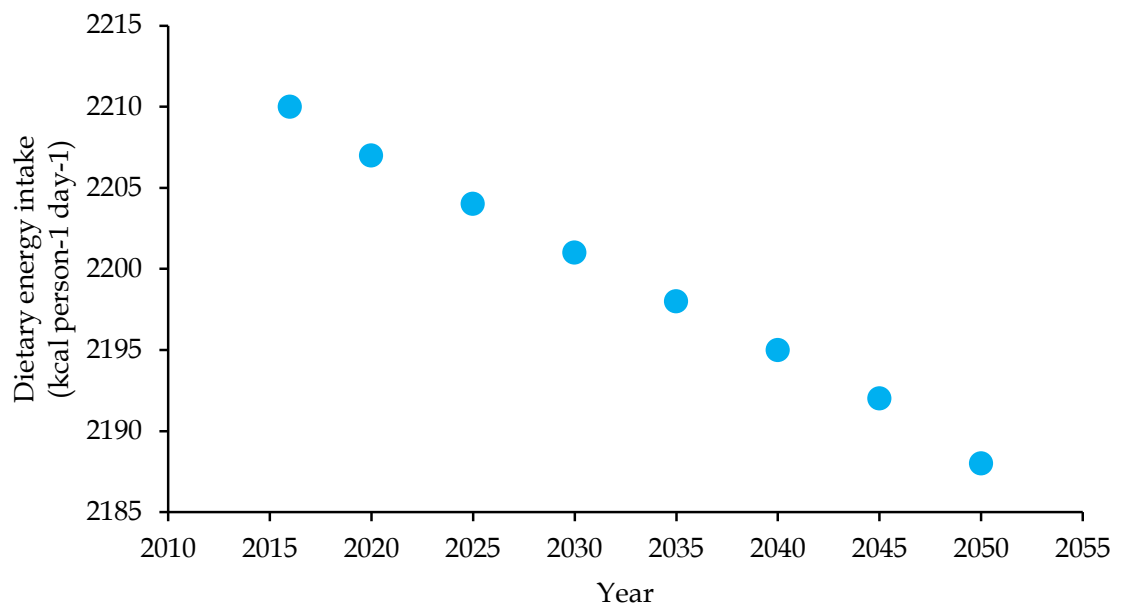

Fig. 1. Predicted per capita dietary energy intake (kcal) by 2050 in Bangladesh.

\section{Daily protein intake from rice}

The DRI (Dietary Reference Intake) is 0.8 grams protein per kilogram body weight (Gabrielle et al., 2008). For the average sedentary women $(57.5 \mathrm{~kg})$ and men $(70 \mathrm{~kg}), 46$ and 56 grams of protein intake per day is required respectively. Approximately $45.87 \%$ of the daily recommended protein comes from the current rate of rice consumption (367 g provides $28.9 \mathrm{~g}$ of protein) and it will further be continuing to get $28.6 \mathrm{~g}$ protein from $363 \mathrm{~g}$ per capita rice intake in 2050 as projected (Table 2). Currently, we are getting an average of $7.90 \%$ rice protein from our well adopted BRRI HYVs and expected to increase rice protein up to 9.0 and $10.0 \%$ through our newly released HYVs, which will enable to increase $12.22 \%$ and $26.58 \%$ more protein supplementation from rice only in our food table by 2030 and 2050 respectively (Table 2).

\section{Desire characteristics of future HYV}

New HYVs should also be considered for specific physicochemical traits such as high apparent amylose content (>25\% AAC) with soft gel consistency (Soft GC, >61-100 mm), translucent (Tr) and long slender to medium slender size and shape grain, etc. Based on the consumer's preference for non-sticky soft rice, these types of rice may be popular in our population in the coming days. The specific grain quality characteristics such as whiteness, broken rice, shape, apparent amylose content

Table 2. Per capita protein intake per day from plant source (Rice).

\begin{tabular}{ccccccc}
\hline Year & Source & $\begin{array}{c}\text { Per capita rice } \\
\text { consumption } \\
\left(\text { g person }^{-1} \text { day }^{-1}\right)\end{array}$ & $\begin{array}{c}\text { Protein }(\mathrm{g}) \text { from } \\
\text { plant source } \\
\text { (HYVs having } \\
\sim 7.9 \% \text { protein) }\end{array}$ & $\begin{array}{c}\text { Protein }(\mathrm{g}) \\
\text { plant source } \\
(\text { HYVs having } \\
9 \% \text { protein) }\end{array}$ & $\begin{array}{c}\text { Protein }(\mathrm{g}) \text { plant } \\
\text { source (HYVs } \\
\text { having 10\% pro- } \\
\text { tein) }\end{array}$ & $\begin{array}{c}\text { Increased } \\
(\%)\end{array}$ \\
\hline 2016 & HIES, BBS & 367 & 28.993 & - & - & - \\
2030 & Projected & 365 & 28.835 & 32.85 & - & 12.22 \\
2050 & Projected & 363 & 28.677 & - & 36.3 & 26.58 \\
\hline
\end{tabular}

Average $70 \mathrm{~kg}$ body wt. human requires $56 \mathrm{~g}$ protein (including both vegetable and animal sources) per day (0.8 $\mathrm{g} \mathrm{kg}^{-1}$ body wt.). HYV denotes high yielding variety. 
(AAC\%), aroma, cooking quality such as gel consistency (GC), and chalkiness influenced the consumers' and producers' preference. Nutraceutically enriched black rice, antioxidant, low GI, Zn, Fe, and Vitamin A enriched advance breeding materials should be screened to get the above mentioned desired grain quality and nutritional characteristics for newly superior HYVs. Estimation of the molar ratio of Phytate (PA) to minerals is a very important parameter for understanding the bioavailability of minerals since low phytate containing rice is desirable for plant breeders (Shozib et al., 2017b).

\section{Nutraceutical rice varieties in Bangladesh}

BRRI has identified a number of nutraceutical enriched HYVs such as three low glycemic index rice namely BR16 (GI 52.4), BRRI dhan 46 (GI 53.1), BRRI dhan69 (GI 54.9), eight Zn enriched HYVs namely BRRI dhan42 (27.12 ppm), BRRI dhan43 (27.17 ppm) for Aus season, BRRI dhan62 (19.0 ppm), BRRI dhan72 (22.0 ppm) for Aman season, BRRI dhan64 (24.0 ppm), BRRI dhan74 (24.40 ppm), BRRI dhan84 (27.60 ppm), BRRI dhan100 (25.7 ppm) for Boro season, two thiamin (Vit- $\left.\mathrm{B}_{1}\right)$ and riboflavin $\left(\mathrm{VitB}_{2}\right)$ enriched BRRI dhan42, BRRI dhan43, four antioxidant-enriched HYVs namely BRRI dhan84 (TPC $37.74 \mathrm{mg}$ GAE), BR5 (TPC $25.30 \mathrm{mg}$ GAE), BRRI dhan88 (TPC $23.07 \mathrm{mg}$ GAE) and one GABA (gamma aminobutyric acid) enriched pre-germinated brown rice namely BRRI dhan31 (Shozib et al., 2017a; Shozib et al., 2017b; Shozib et al., 2018a; Siddiquee et al., 2017). For BRRI dhan29 containing the GR2E Golden Rice trait, concentrations of the b-carotene equivalents (BCEs) are approximately $12.0 \mathrm{\mu gg}^{-1}$ (ppm) (Donald, 2018). Besides these 17 nutraceuticals enriched HYVs, BRRI is conducting diversified research activities with anthocyanin enriched black rice in both animal and human cell lines to combat non-communicable diseases such as cancer, diabetes, and hypertension.

\section{Over polishing $(\geq 10 \%)$ effect on nutritional loss}

In 2007, Lamberts et al., reported that the mineral content is the highest in the bran $(61.0 \%)$, followed by outer endosperm (23.7\%), core endosperm $(11.6 \%)$, and the lowest in the middle endosperm (3.7\%). Proteins, minerals, and starch were not uniformly distributed in the brown rice kernel. Bran $(\mathrm{DOM}<9 \%)$ contained most of the minerals $(61.0 \%)$. Shozib et al., (2018a) found variation in $\mathrm{Zn}$ content with increasing polishing time from 80 seconds to 180 seconds at DOM on a laboratory scale. Rice samples were dehusked by Satake Rice mill, followed by $80,100,120$, 140, 160, and 180 second polishing in a Grainman rice polisher (USA) to get 8.5, 9.0, 9.5, 9.9, 10.3, and $10.6 \%$ polished rice (clean rice or milled rice) respectively as an average scale for 5 HYVs such as BR25, BRRI dhan36, BRRI dhan42, BRRI dhan 43 and BRRI dhan64 in the mineral analysis. At 80 seconds of polishing, DOM varied ranges from 6.19 to $10.46 \%$ for five selected HYVs whose grain size and shape are also varied from small and medium grain, long and slender grain, medium, and bold grain, etc. Zn content of BR25, BRRI dhan36, BRRI dhan42, BRRI dhan43, and BRRI dhan64 were 24.70, 23.60, $27.12,27.17$, and $24.46 \mathrm{ppm}$ respectively at 80 seconds of polishing. Zn content of BR25, BRRI dhan36, BRRI dhan42, BRRI dhan43, and BRRI dhan64 was 21.30, 20.43, 24.21, 23.90, and 22.10 ppm respectively at 140 seconds of polishing where DOM varied ranges from 7.78 to $11.28 \%$. Finally, $\mathrm{Zn}$ content of BR25, BRRI dhan36, BRRI dhan42, BRRI dhan43, and BRRI dhan64 were 18.21, 17.34, 20.43, 27.17, and 20.10 ppm respectively at 180 seconds of polishing where DOM varied ranges from 10.15 to $12.02 \%$. Authors have demonstrated how $\mathrm{Zn}$ content and DOM of five different BRRI HYVs significantly varied at different polishing time ranges from 80 seconds to 180 seconds considering grain size and shape into account. For citation, in the commercial milling 
process a nutraceutically enriched BRRI dhan 42 can lose a maximum up to $24.7 \%$ of $\mathrm{Zn}$ at $18.4 \%$ degree of milling (DOM). The more we will increase the degree of milling the more nutrient we will lose. In this regard, $1^{\text {st }}$ pass which means $7.4 \%$, DOM is enough to get 27.1 ppm of Zn from BRRI dhan42. On the other hand, $11 \%$ extra milling will produce whitening starch compounds only but fewer or trace amounts of fiber, ash, and fat which will cause health hazard directly.

Since over-polishing $(>10 \%)$ of rice does not possess much nutrients, fiber, vitamins, and minerals so, it will not be able to bring any health benefit rather it is a threat of some non-communicable diseases. We have to fix rice milling $\leq 10 \%$ DOM through any interventions either from the government and NGOs or both so that we will be able to get the maximum benefit of nutraceutical properties of rice indeed. Escaping an extra $10 \%$ DOM loss will help to achieve productivity double in quantity. Consuming a lesser degree of milling rice will not only assist in the productivity doubling process but it will qualitatively improve our nutritional status as well. Recently released BRRI HYV's grain types are recorded as long slender, long bold or medium slender such as BRRI dhan80, BRRI dhan81, BRRI dhan84, BRRI dhan85, BRRI dhan86, BRRI dhan87, BRRI dhan88, BRRI dhan89. So, these HYVs need not to be over-polished.

Table 3. Loss percentage of $\mathrm{Zn}$ content in BRRI dhan 42 during commercial milling (unpublished data of GQN Division, BRRI, 2019).

\begin{tabular}{cccc}
\hline Pass & DOM $(\%)$ & Zn $(\mathrm{ppm})$ & Zn loss $(\%)$ \\
\hline $1^{\text {st }}$ & 7.4 & 27.1 & - \\
$2^{\text {nd }}$ & 10.9 & 25.3 & 6.9 \\
$3^{\text {rd }}$ & 13.9 & 22.6 & 16.9 \\
$4^{\text {th }}$ & 16.4 & 21.8 & 19.6 \\
$5^{\text {th }}$ & 18.4 & 20.4 & 24.7 \\
\hline
\end{tabular}

Note: DOM denote degree of milling; ppm indicate parts per million Aspects of rice-based bakery products in
Bangladesh

BRRI scientists have formulated nutraceutically enriched rice-based popular bakery food products such as rice biscuits, rice cakes, rice bread, etc. These rice-based bakery products are gluten-free and consist of high protein, minerals $(\mathrm{Zn} \mathrm{Fe}, \mathrm{Ca}$, and $\mathrm{P})$, antioxidants, vitamins such as thiamin and riboflavin, etc. Scientists also formulated energy-dense rice cookies or biscuits (Energy Density; ED 5.15, $100 \mathrm{~g}$ serving provides 515 $\mathrm{kcal}$, high protein $>10 \%$ and high-fat content of $25 \%)$ which are low cost, safe, and nutritionally balanced (Shozib, 2018b). Ricebased products require lesser amount of carbohydrates than we have usually taken as cooked rice for a single meal. For example, 100 $\mathrm{g}$ serving rice-based food items required $50 \mathrm{~g}$ carbohydrate to generate $500 \mathrm{kcal}$ and on the other hand $125 \mathrm{~g}$ raw rice required to generate the same quantity of energy by consuming cooked rice for a single meal $(1.0 \mathrm{~g}$ carbohydrate generate $4.0 \mathrm{kcal}$ energy).

Rice-based products are supposed to be formulated in an ideal proportion of carbohydrate, fat, protein ratio as 50:30:20. So there is a huge scope in increasing the average income of small-scale food producers especially learned farmers and local bakery owners in adopting nutraceutically enriched rice production.

Rice-based bakery products can potentially be used to minimize malnutrition of the most vulnerable portion of our population especially street children. Since street children are the most vulnerable group of population coming to fight to gild the streets for their habitual abode and livelihood drifted into a nomadic life. These children are generally malnourished due to their deprivation of health care and improved nutrition. In 2021, Saima et al., conducted a baseline survey on street children of the capital city, Dhaka on both boys and girls of 4-12 
years. A total of 384 street children were subjected to study a baseline survey. The sample size was fixed by addressing Cochran equation. Among the respondents $63 \%$ were male and $37 \%$ were female from street children population of 384 . Survey took place at 20 different hot spots covering both garts of Dhaka city north and south. We have observed the recommended dietary intake per day from 4 years to 12 years old male boys and found 27 to $59 \%$ deficiency in our male population samples of 243. Similarly, we also observed the recommended dietary intake per day from four years to 12 years old female girls and found 28 to $56 \%$ deficiency in our female population samples of 141. Since our energy dense rice cake (EDRC) has a potential of providing $500 \mathrm{kcal}$ energy per $100 \mathrm{~g}$ serving so, we could predict that incorporating our improved rice-based product once a day along with their daily regular intake, it will able to mitigate nutritional gap by 64 to $100 \%$ for street boys and noticeably 70 to $100 \%$ for girls. We have prepared energy dense rice biscuit (EDRB, 3.6\% moisture, $515 \mathrm{kcal}$ per $100 \mathrm{~g}$ of serving) and energy dense rice cake (EDRC, $5.0 \%$ moisture, $500 \mathrm{kcal}$ per $100 \mathrm{~g}$ of serving).
EDRC was found prepared than EDRB in impact study when the respondents were given choice of rice-based bakery items intake for four months long period. Finally, a total of 32 respondents took part in a four months period impact study on EDRC from street children population. All anthropometric and biochemical data such as CBC (Complete Blood Count), Hemoglobin, CRP, Prealbumin etc. were collected at both the starting (Day 0) and the end time (Day 120) of the impact survey of selected 32 respondents. Respondents were given $100 \mathrm{~g}$ serving of EDRC every day (Rice cake) to 32 street children samples for 4 months period along with their normal food intake. Our data revealed that malnutrition related parameters specially CRP (decreased) and Prealbumin (Increased) are significantly improved during four months supplementary intake of extra $500 \mathrm{kcal}$ per 100 g serving of EDRC in tested street children's samples which resemble the possible impact of EDRC on street children. Rice-based bakery products specially EDRB and EDRC can potentially be used in school feeding nutritional programme and disaster management in Bangladesh.

Table 4. Baseline survey on daily dietary intake of street children (age 4-12) for boys.

\begin{tabular}{|c|c|c|c|c|c|c|c|c|c|c|c|}
\hline \multirow{10}{*}{ 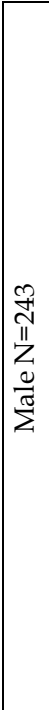 } & $\underset{\pi}{\infty}$ & 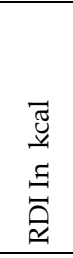 & 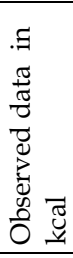 & 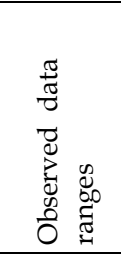 & 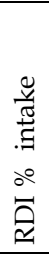 & $\begin{array}{l}\mathbb{Z} \\
\ddot{~} \\
\Xi \\
\tilde{\Xi} \\
\tilde{J}\end{array}$ & $\begin{array}{l}\overrightarrow{0} \\
4 \\
\overrightarrow{0} \\
0 \\
0 \\
0 \\
0\end{array}$ & 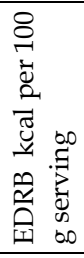 & 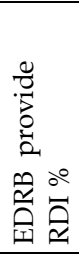 & 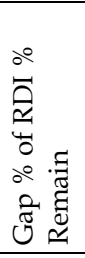 & 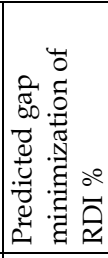 \\
\hline & $4(n=13)$ & 1303 & 955 & $600-1100$ & 73 & 348 & 27 & 515 & 40 & -13 & 100 \\
\hline & $5(n=11)$ & 1362 & 865 & $630-1210$ & 63 & 497 & 37 & 515 & 38 & -1 & 100 \\
\hline & $6(n=14)$ & 1403 & 852 & $670-1180$ & 61 & 551 & 39 & 515 & 37 & 3 & 97 \\
\hline & $7(\mathrm{n}=21)$ & 1507 & 994 & $720-1187$ & 66 & 513 & 34 & 515 & 34 & 0 & 100 \\
\hline & $8(n=20)$ & 1624 & 919 & $620-1170$ & 57 & 705 & 43 & 515 & 32 & 12 & 88 \\
\hline & $9(\mathrm{n}=35)$ & 1750 & 865 & $620-1250$ & 49 & 885 & 51 & 515 & 29 & 21 & 79 \\
\hline & $10(\mathrm{n}=32)$ & 1890 & 877 & $670-1300$ & 46 & 1013 & 54 & 515 & 27 & 26 & 74 \\
\hline & $11(n=40)$ & 2038 & 866 & $620-1400$ & 42 & 1172 & 58 & 515 & 25 & 32 & 68 \\
\hline & $12(\mathrm{n}=57)$ & 2200 & 893 & $650-1280$ & 41 & 1307 & 59 & 515 & 23 & 36 & 64 \\
\hline
\end{tabular}

EDRB: Energy dense rice biscuit; ED: Energy Density: RDI: Recommended dietary intake. 
Table 5. Baseline survey on daily dietary intake of street children (age 4-12) for girls.

\begin{tabular}{|c|c|c|c|c|c|c|c|c|c|c|c|}
\hline \multirow{10}{*}{ 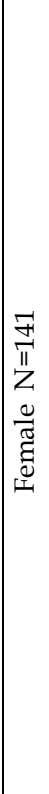 } & $\stackrel{8}{<}$ & 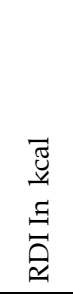 & 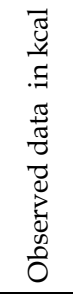 & 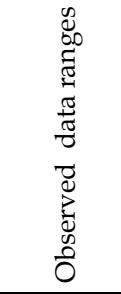 & 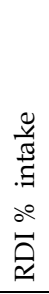 & $\begin{array}{l}\tilde{\Xi} \\
. \\
\Xi \\
\tilde{\Xi}\end{array}$ & 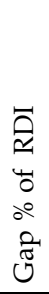 & 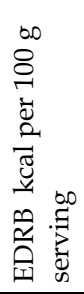 & 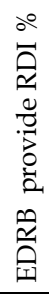 & 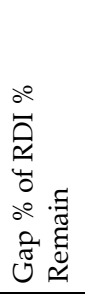 & 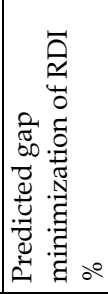 \\
\hline & $4(\mathrm{n}=12)$ & 1244 & 898 & $625-1110$ & 72 & 346 & 28 & 515 & 41 & -14 & 100 \\
\hline & $5(\mathrm{n}=19)$ & 1202 & 850 & $700-1300$ & 71 & 352 & 29 & 515 & 43 & -14 & 100 \\
\hline & $6(\mathrm{n}=11)$ & 1300 & 769 & $658-1020$ & 59 & 531 & 41 & 515 & 40 & 1 & 99 \\
\hline & $7(\mathrm{n}=28)$ & 1403 & 884 & $620-1180$ & 63 & 519 & 37 & 515 & 37 & 0 & 100 \\
\hline & $8(\mathrm{n}=11)$ & 1502 & 1002 & $820-1210$ & 67 & 500 & 33 & 515 & 34 & -1 & 100 \\
\hline & $9(n=13)$ & 1638 & 767 & $672-970$ & 47 & 871 & 53 & 515 & 31 & 22 & 78 \\
\hline & $10(n=15)$ & 1777 & 931 & $670-1170$ & 52 & 846 & 48 & 515 & 29 & 19 & 81 \\
\hline & $11(n=21)$ & 1942 & 863 & $650-1025$ & 44 & 1079 & 56 & 515 & 27 & 29 & 71 \\
\hline & $12(\mathrm{n}=11)$ & 2070 & 930 & $850-1270$ & 45 & 1140 & 55 & 515 & 25 & 30 & 70 \\
\hline
\end{tabular}

EDRB: Energy dense rice biscuit; ED: Energy Density: RDI: Recommended dietary intake

\section{ACTION Plan (2021-2050)}

To fulfill the SDG goal on nutritional security, Grain Quality and Nutrition (GQN) Division of BRRI should follow the proposed action plan (Table 6) through 10 year period of interval (Table 7) from 2020 to 2050. A total of 10,500 (estimated) genebank entities of BRRI including advanced breeding lines, BRRI released HYVs and local germplasms will be evaluated for physicochemical, nutraceutical properties during these three decades from 2021-2050. The action mapping plan is divided into two separate themes such as research and development, and dissemination. Themes are divided into three phases such as primary, secondary, and tertiary phases. Further, it is segmented in several progresses such as characterization, baseline survey, product formulation, sensory evaluation, training, and dissemination.

In the progress of characterization of a primary phase several activities will be taken to fully characterize germplasm such as physicochemical (Physical and Chemical properties), nutraceutical (Nutrition and Medicinal properties), minerals profiling (Macro and Micronutrients), heavy metal profiling (As, $\mathrm{Cd}, \mathrm{Pb}, \mathrm{Ni}, \mathrm{Cr}$ ), aroma profiling, fatty acid profiling (Rice bran, Rice Bran Oil), amino acid profiling, prebiotics production (Rice straw and Rice Bran), vitamin profiling (Water- and fat-soluble vitamins), antioxidant profiling, and proximate analysis.

The baseline survey will be followed by rice grain characterization and it will come in the second phase including several activities such as a baseline survey on rice grain preferences of farmers, millers, and consumers and baseline survey on rice-based products of manufacturers and consumers. Few superior rice cultivars or HYVs will be selected for three following decades based on consumers' preference through the above mentioned activities (Table 6).

Product formulation will come to $3^{\text {rd }}$ progress in tertiary phase with several actions such as product profiling of quality rice grain,

112 Shozib et al. 
rice-based nutrient dense products formulation (Value added rice-based products), multiple rice-based food products for disease management, the residual effect of herbicides and pesticides of rice grain and rice-based products, proximate analysis of rice-based products, energy estimation and quality analysis of rice-based food products. The sensory evaluation will be followed by product formulation in tertiary phases which includes several activities such as quality rice grain selection and rice-based nutrient dense products formulation (Value added ricebased products). Dissemination will be adopted at the tertiary phase including two stages such as training and demonstration with several actions such as training for food manufacturer, rice miller and RBO miller and demonstration in bakery and food industries (Table 7).

Table 6. Action plan for ensuring safe rice consumption with superior grain quality and nutrition.

\begin{tabular}{|c|c|c|c|}
\hline Action title & \multicolumn{3}{|c|}{ Ensuring safe rice consumption with superior grain quality and nutrition } \\
\hline Theme & Phase & Progress & Activities \\
\hline \multirow{4}{*}{$\begin{array}{l}\text { Research and } \\
\text { Development }\end{array}$} & Primary & Characterization & $\begin{array}{l}\text { 1. Physicochemical (Physical and Chemical properties) } \\
\text { 2. Nutraceutical (Nutrition and Medicinal properties) } \\
\text { 3. Minerals profiling (Macro and Micronutrients) } \\
\text { 4. Heavy metal profiling ( } \mathrm{As}, \mathrm{Cd}, \mathrm{Pb}, \mathrm{Ni}, \mathrm{Cr} \text { ). } \\
\text { 5. Aroma profiling } \\
\text { 6. Fatty acid profiling (Rice bran, Rice bran oil) } \\
\text { 7. Amino acid profiling } \\
\text { 8. Prebiotics (Rice straw and Rice bran) } \\
\text { 9. Vitamin Profiling (Water- and fat soluble vitamins) } \\
\text { 10. Antioxidant profiling } \\
\text { 11. Proximate analysis }\end{array}$ \\
\hline & Secondary & Baseline survey & $\begin{array}{l}\text { 1. Baseline survey on rice grain preferences of farmers, } \\
\text { millers and consumers } \\
\text { 2. Baseline survey on rice-based products of } \\
\text { manufacturers and consumers }\end{array}$ \\
\hline & \multirow[t]{2}{*}{ Tertiary } & $\begin{array}{l}\text { Product } \\
\text { formulation }\end{array}$ & $\begin{array}{l}\text { 1. Product profiling of quality rice grain } \\
\text { 2. Rice-based nutrient dense products formulation (Value } \\
\text { added rice-based products) } \\
\text { 3. Multiple rice-based food products for disease } \\
\text { management } \\
\text { 4. Residual effect of herbicides and pesticides of rice grain } \\
\text { and rice-based products } \\
\text { 5. Proximate analysis of rice-based products } \\
\text { 6. Energy estimation } \\
\text { 7. Quality analysis of rice-based food products }\end{array}$ \\
\hline & & Sensory evaluation & $\begin{array}{l}\text { 1. Quality rice grain selection } \\
\text { 2. Rice-based nutrient dense products formulation (Value } \\
\text { added rice-based products) }\end{array}$ \\
\hline \multirow[t]{2}{*}{ Dissemination } & \multirow[t]{2}{*}{ Tertiary } & Training & $\begin{array}{l}\text { 1. Training for food manufacturer, rice miller and RBO } \\
\text { miller }\end{array}$ \\
\hline & & Demonstration & 1. Demonstration in bakery and food industries \\
\hline
\end{tabular}




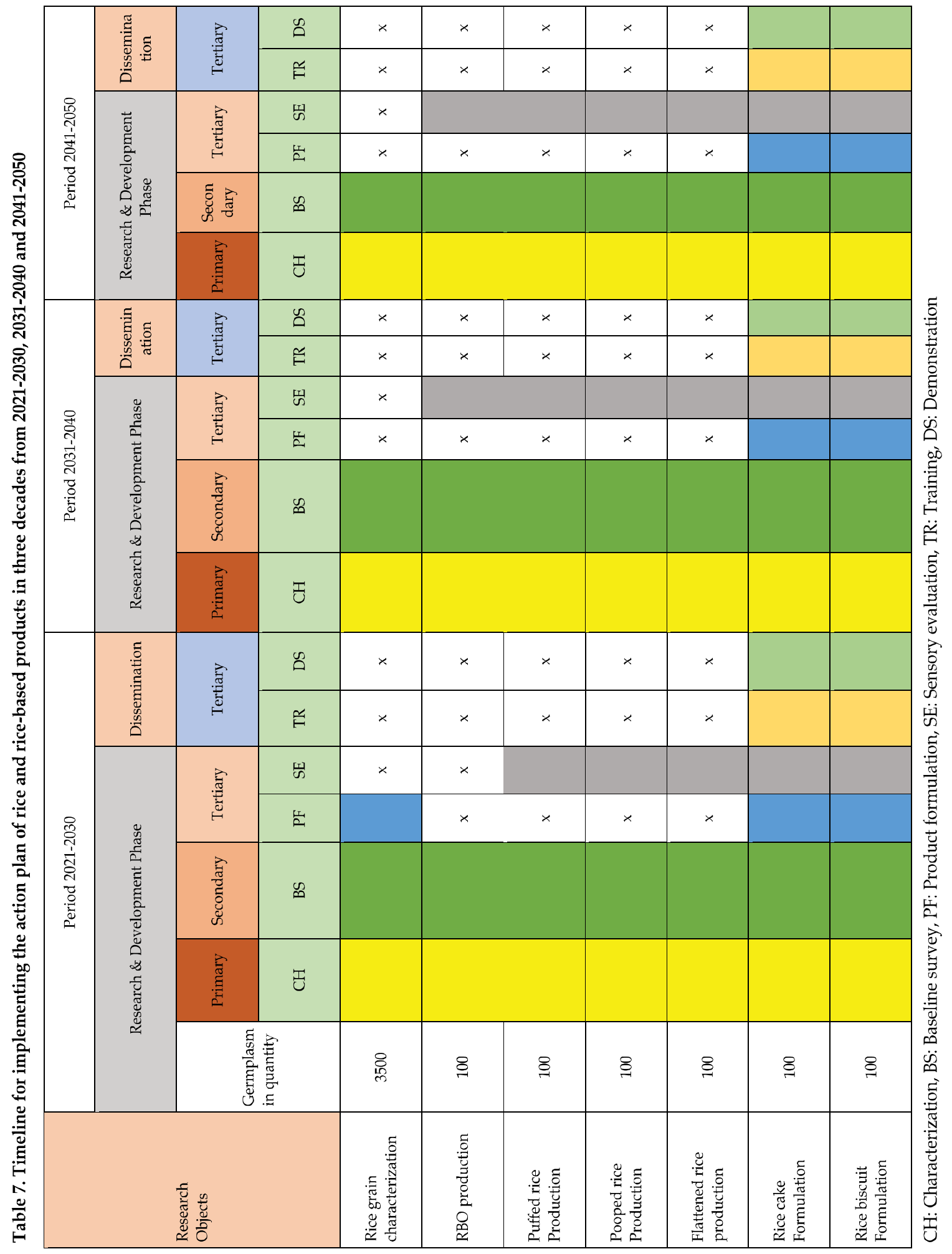

114 Shozib etal. 


\section{CONCLUSION}

Rice is the most valued cereal crop to combat non-communicable diseases (NCDs) with its versatile nutraceutical properties embedded in it. We predicted per capita rice consumption of $365 \mathrm{~g}$ and $363 \mathrm{~g}$ (dry wt. basis) in 2030 and 2050 , respectively will help to attain the current trends of $59.0 \%$ of calorie intake from rice only. We expect to increase rice protein from $7.9 \%$ to $9 \%$ and $10 \%$ through our newly released BRRI HYVs which will enable us to increase $12.22 \%$ and $26.58 \%$ more protein supplementation from rice only in our food table by 2030 and 2050, respectively. Nutraceutically enriched rice-based food items have the potential to be popular among Bangladeshi people. This will play a vital role to gradually reduce overall rice consumption and preferably help sustain food security in Bangladesh in a way to properly utilizing the rice keeping the required dietary allowance intake. Rice-based energy dense dry bakery products can be utilized in the disaster management programme and school feeding nutritional programme for mitigation of malnutrition. Besides, nutraceutical rice-based food formulation requires a lesser amount of carbohydrate so its glycemic load is usually low and these products will help in noncommunicable disease management especially diabetics in Bangladesh.

\section{RECOMMENDATIONS}

- Nutraceutical enriched rice should be consumed periodically (thrice a week) or should intake a little portion mixed with white rice daily.

- Over polished (>10\%) milled rice should not be eaten to avoid bowel related diseases.

- Gluten-free energy-dense rice biscuit (EDRB) has the potential to be utilized for malnutrition minimization approaches including school feeding nutritional programmes and disaster management programme in Bangladesh.
- Nutraceutical enriched such as antioxidantenriched, micronutrient enriched, anthocyanin enriched rice varieties can be used for rice-based bakery products with a special interest in combating NCDs disease such as cancer, diabetic, and heart disease for the Bangladeshi population.

- Intergovernmental initiatives between the Ministry of Agriculture and Ministry of Disaster Management and Relief can upscale EDRB biscuits as dry food for emergency relief operation and disaster management.

\section{ACKNOWLEDGEMENTS}

The authors wish to thank anonymous reviewers for their suggestions, which significantly improved this article.

\section{AUTHORS' CONTRIBUTION}

HBS generated idea; MUS, MARS and MAAM coordinated the research; HBS developed methodology; HBS, MAS and NMFR provided scientific insights; HBS, NMFR and MAAM gathered data, carried out analysis and synthesis. HBS did writings for all versions of the manuscript; MUS, MARS, SMHAR and MSK performed critical review and editing; All authors read and approved the final manuscript.

\section{DECLARATION OF INTERESTS}

A version of the paper was published in a book 'Doubling Rice Productivity in Bangladesh' in 2020 by the Bangladesh Rice Research Institute (BRRI), Gazipur 1701, Bangladesh to commemorate BRRI's $50^{\text {th }}$ anniversary. The Bangladesh Rice Journal has prior knowledge of the book publication and does not see any conflict of interest.

\section{REFERENCES}

AOAC (Association of Official Agricultural Chemists). 1995. Official procedure of mineral estimations ( $\mathrm{Zn}$, $\mathrm{Fe}$ and $\mathrm{Ca}$ ) of Association of Official Agricultural Chemists (AOAC).

ASEAN Manual of Food Analysis. 2011. Regional Centre of ASEAN Network of Food Data System. First

Grain Quality Research 115 
edition published in 2011 by Institute of Nutrition, Mahidol University, Thailand.

BBS-HIES (Bangladesh Bureau of Statistics-Household Income and Expenditure Survey). 2016. Preliminary report on household income and expenditure survey (HIES) 2016, Bangladesh Bureau of Statistics (BBS), Statistics and Informatics Division (SID), Ministry of Planning, Government of the People's Republic of Bangladesh.

Donald, M. 2018. Memorandum discussion on Golden Rice in Bangladesh (Personal communication)

Firouzi, S and R Mohammad. 2010. Effect of the size of perforated screen and blade-rotor clearance on the performance of Engelberg rice whitener. African Journal of Agricultural Research, 5. DOI: 10.5897/ AJAR09.542

Fukai, S and I Godwin. 2007. Genotypic variation of iron partitioning in rice grain. Journal of the Science of Food and Agriculture, 87. DOI: 10.1002/jsfa.2961.

Gabrielle, M, M Turner, D B Joshua, C David, G Lise, A G Amber. 2008. Changes in nutrient intake and dietary quality among participants with type 2 diabetes following a low-fat vegan diet or a conventional diabetes diet for 22 weeks. Journal of the American Dietetic Association, 1936-1645.

Haffner, S M, M P Stern, H P Hazuda, J A Pugh, J K Patterson. 1986. Hyperinsulinemia in a population at high risk for non-insulin-dependent diabetes mellitus. N. Engl. J. Med., 315: 220-224.

Hu, C, J Zawistowski, W Ling, D D Kitts. 2003. Black rice (Oryza sativa L. indica) pigmented fraction suppresses both reactive oxygen species and nitric oxide in chemical and biological model systems. J Agric Food Chem, 51: 5271-5277.

Hudson E A, P A Dinh, T Kokubun, M S J Simmonds, A Gescher. 2000. Characterization of potentially chemopreventive phenols in extracts of brown rice that inhibit the growth of human breast and colon cancer cells. Cancer Epidem Biomar, 9: 1163-1170.

Institute of Medicine (US), 1998. Standing Committee on the Scientific Evaluation of Dietary Reference Intakes and its Panel on Folate, Other B Vitamins, and Choline. Dietary Reference Intakes for Thiamin, Riboflavin, Niacin, Vitamin B6, Folate, Vitamin B12, Pantothenic Acid, Biotin, and Choline. Washington (DC) : National Academies Press (US) 5,Riboflavin. https://www.ncbi.nlm. nih.gov/books/NBK114322

International Rice Research Institute (IRRI), 2013. Standard Evaluation System for Rice. $5^{\text {th }}$ edn. IRRI, Manila, Philippines.
Iqbal, S, M I Bhanger, F Anwar. 2005. Antioxidant properties and components of some commercially available varieties of rice bran in Pakistan. Food Chem, 93: 265-272.

Itani, T, H Tatemoto, M Okamoto, K Fujii, N Muto. 2002. A comparative study on antioxidative activity and polyphenol content of colored kernel rice. J. Jpn. Soc. Food Sci., 49: 540-543.

Kabir, M S, M U Salam, A Chowdhury, N M F Rahman, K M Iftekharuddaula, M Rahman, M Rashid, S S Dipti, A Islam, M Latif, A Islam, M Hossain, B Nessa, T H Ansari, M A Ali, and J K Biswas. 2015. Rice Vision for Bangladesh: 2050 and Beyond. Bangladesh Rice J., 19: 1-18.

Kabir, M S, M U Salam, A K M S Islam, M A R Sarkar, M A A Mamun, M C Rahman, B Nessa, M J Kabir, H B Shozib, M B Hossain, A Chowdhury, M Nasim, K M Iftekharuddaula, M S Hossain, M K A Bhuiyan, B Karmakar, M S Rahman, M M Haque, M T Khatun, M P Ali, S M H A Rabbi, P L Biswas, E S M H Rashid, N M F Rahman. 2020. Doubling rice productivity in Bangladesh: A way to achieving SDG 2 and moving forward. Bangladesh Rice Journal, 24 (2): 1-47.

Keh, D S. 2004. The SAS ${ }^{\circ}$ Calculations of Areas Under the Curve (AUC) for Multiple Metabolic Readings. Department of Biostatistics \& Department of Diabetes, City of Hope National Medical Center, Duarte, CA, USA. Www.lexjansen.com/wuss/2004/posters/ c_post_the_sas_calculations_.pdf

Lamberts, L, E Bie, V Greet, D Wim, M Veerle, D J Walter. 2007. Effect of milling on color and nutritional properties of rice. Food Chemistry, 100: 1496-1503. DOI: 10.1016/j.foodchem.2005.11.042.

Ling, W H, Q X Cheng, J Ma, T Wang. 2001. Red and black rice decrease atheroscletoric plaque formation and increase antioxidant status in rabbits. J Nutr, 131: 1421-1426.

Morimitsu, Y, K Kubota, T Tashiro, E Hashizume, T Kamiya, T Osawa. 2002. Inhibitory effect of anthocyanins and colored rice on diabetic cataract formation in the rat lenses. Int Congr Ser, 1245: 503-508.

National Micronutrient Survey 2011-12 2013: Final report ICDDR, B UNICEF, Bangladesh GAIN Institute of Public Health and Nutrition.

Oktay, M, I Gülçin, O I Küfrevioğlu. 2003. Determination of in vitro antioxidant activity of fennel (Foeniculum vulgare) seed extracts. Lebensm Wiss Technol., 36: 263-271.

Oyaizu, M. 1986. Studies on product of browning reaction prepared from glucose amine. Jpn. J. Nut., 44: 307-315. 
Prapasri, P. E S Tee, K Julia, C Graham, R F Rafael. 2011. J ASEAN Manual of Food Analysis, pp: 103-108.

Prieto, P, M Pineda, M Aguilar. 1999. Spectrophotometric quantitation of antioxidant capacity through the formation of a phosphomolybdenum complex: Specific application to the determination of vitamin E. Anal. Biochem., 269: 337-341.

Psyrogiannis, A, V Kyriazopoulou, A Symeonidis, M Leotsinidis, A G Vagenakis. 2003. Relative iron 'overload' in offspring of patients with type 2 diabetes mellitus: a new component in the conundrum of insulin resistance syndrome. Hormones, 2 (3): 161-168.

Puri, S, D Bhavnita, S Navdeep. 2014. Effect of Degree of Milling (DOM) on Overall Quality of Rice -A Review. International journal of advanced biotechnology and research, 5 .

Saima J, S A S Mahmud, I H Chowdury, M A Siddiquee and H B Shozib. 2021 Formulation of rice based low cost balanced, nutritious and safe diet for the malnourished children. (A annual report has been submitted in PIU-BARC-NATP-2, Dhaka, Bangladesh and Manuscript submitted in press).

Shozib, H B, J Saima, Z S Muhammad, A Samsul, C D Suman, B A Rifat, H Mahedi, M A Siddiqquee. 2018a. Nutritional Properties of Some BRRI HYV Rice in Bangladesh. Vitam Miner, 7 (1): 174.

Shozib, H B, J Saima, C D Suman, A Samsul, B A Rifat, H Mahedi, M Richard, M A Siddiqquee. 2017b. Mineral profiling of HYV rice in Bangladesh. Vitam Miner, 6: 164.

Shozib, H B, B Shourab, J Saima, J. M A Siddiqquee. 2017a. In vivo screening for low glycemic index (GI) rice varieties in Bangladesh and evaluate the effect of differently processed rice and rice products on GI. Biojournal of Science and Technology, 5: m170001.

Shozib, H B, A S M Sultan, B A Rifat, N H Mohammad, K B Jiban, T Jagadish, A A Muhammad, M A Siddiqquee. 2018b. Nutraceutically enriched rice-based food to mitigate malnutrition in Bangladesh. EC Nutrition, 13 (5): 240-249.
Siddiquee, M A, J Saima , Y Kabir, H B Shozib. 2017. BRRI dhan31 generate elevated level of bioactive component, $\gamma$-aminobutyric acid (GABA) at pre-germinated brown rice condition. International Journal of Scientific Research (IJSR), 6 (7): 511-513.

Singleton, V L, R Orthofer, R M Lamuela-Raventos. 1999. Analysis of total phenols and other oxidation substrates and antioxidants by means of Folin-Ciocalteu reagent. Methods Enzymol., 299: 152-178.

Sunanda, D, G Jahida. 2017. Different forms of malnutrition among under five children in Bangladesh: a cross sectional study on prevalence and determinants. BMC Nutrition, 3: 1.

Tian, S, K Nakamura, H Kayahara. 2004. Analysis of phenolic compounds in white rice, brown rice, and germinated brown rice. J Agric Food Chem, 52: 4808-4813.

Welch, R, R D Graham. 1999. A new paradigm for world agriculture: meeting human needs. Productive, sustainable, nutritious. Field Crops Res, 60: 1-10.

Welch, R M, and R D Graham. 2004. Breeding for micronutrients in staple food crops from a human nutrition perspective. J Exp Bot, 55: 353-364.

WHO (World Health Organization). 2003. Diet, nutrition and the prevention of chronic diseases: report of a joint WHO/FAO expert consultation: WHO Technical Report Series, No. 916 Geneva: World Health Organization.

WHO (World Health Organization). 2020. Healthy diet, 29 April 2020.

Yawadio, R. Tanimori, S. Morita, N. 2007. Identification of phenolic compounds isolated from pigmented rice and their aldose reductase inhibitory activities. Food Chem, 101: 1616-1625.

Zhang, M, B Guo, R C J Zhang, Z We, Z Z Y Xu. X Tang. 2006. Separation, purification and identification of antioxidant compositions in black rice. Agric Sci China, 5: 431-440.

Zhou, Z, K Robards, S Helliwell, C Blanchard, 2004. The distribution of phenolic acids in rice. Food Chem, 87: 401-406. 
118 Shozib et al. 